\title{
Barriers of Systemic Innovation to Increase Productivity of Engineering and Construction Industries of the World
}

\author{
Ali Shabanesfahani ${ }^{1}$, Mohammad Reza Faraj Tabrizi ${ }^{2}$ \\ ${ }^{I}$ Perdana School of Science, Technology and Innovation Policy, University Technology Malaysia \\ ${ }^{2}$ International Business School, Universiti Teknologi Malaysia
}

\begin{abstract}
This write up discusses the barriers that characterize systemic innovation in the construction industries. It started with construction industry overview and the innovations in the industry generally. It then focuses on systemic innovations in the industry with emphasis on the barriers to systemic innovations that exist within it. It therefore gave recommendation based on the identified problems.
\end{abstract}

Keywords: Systemic innovation, productivity, engineering and construction industries

\section{Introduction}

The building and construction $(\mathrm{B} \& \mathrm{C})$ industry is one of the most vital in present economies. After connected industries (such as manufacturers of building produce and system, designers and property managers) are encompassed, the industry reports for concerning 15 each cent of the nationwide product of most nation states, including Malaysia. It is important to know that the higher the level of innovation in the construction industry, the larger the likelihood of its contribution to commercial growth. Unfortunately, in most nation states, there is an understanding that the industry is not usually innovative, but there are rooms for improvement. Even though the engineering and construction industry is the largest industry in the world, yet the productivity of the traditional sectors used has been laggard as compared to other industrial sector. Reports in past have recognized such setbacks as poor rates of investment in research and innovative (R\&D), fragmented supply shackles and lack of coordination amid academia and industry in research hobbies (Dulaimi, Ling, Ofori, \& De Silva, 2002) [9].

Most firms concur to innovation as a key avenue to productivity, but some firms halt at lip service. Including innovation in mission statements does not translate to innovativeness automatically.

Next there are companies that endeavor to isolate innovation in a "Skunk Works," keeping its work separate from "normal" business (Skunk Works is a word coined by Lockheed in 1943 that nowadays refers to a way a cluster of people who, in order to achieve infrequent result, work on a project in a method that is beyond the usual rules.) Company theory being what it is, there is an easy explanation for why innovation is believed so important: there just aren't extremely countless examples of firms who have upheld accomplishment-lacking concentrating on producing across innovation. It has come to be a truism that innovation is important, firms anticipated to innovate, and as well pay attention keenly to its processes.

This paper depicts the relation between innovation and its impact on the construction and engineering sector that are considered as project-based sector. It also discusses the importance of systemic innovation in the construction and engineering sector of the world. The author takes many views of the articles related to the study and investigates on the role of innovation in the construction and engineering sector. Engineering and construction sector are considered as a project based industries and are the largest industrial sector in the global economy. Thus they need to be innovative and become a prevalent emerging industry in order to compete globally. However, it gave an express discussion on the root cause of the barriers to the systemic innovations in the construction industry, thereby stating some recommended solutions to them.

The write up is made up of six parts; following the introduction is the overview of the construction industry, which includes its definition and some discussions on it. The third part accounts for the innovations in the construction industry with the definition of innovation generally and also in relation to construction industries with examples. In the fourth Part, discussions on the barrier to systemic innovation in the construction industry were given, leading to the relevant solutions in the fifth part. Conclusion and recommendations follow on the sixth part, which is also the last part.

\section{Construction Industry}

Business dictionary defines construction industry as "the sector of national economy that is engaged in preparation of land and construction, alteration, and repair of buildings, structures, and other real property" (BusinessDictionary, 2012) [6]. Construction is a high hazard industry that comprises a wide range of activities involving the ones mentioned above. Examples include residential construction, bridge erection, roadway paving, excavations, demolitions, and large scale painting jobs (DOL, 2012) [7]. With all indications, this is an 
industry that cannot be joked with in any economy since it is responsible for the practical building up of the physical structures that make living easier.

The performance of the construction industry in words of productivity, quality and product functionality is believed low among other industries, and a low rate of innovation has been endowed as the main explanation to this situation (D. Gann, 2000; G. Winch, 1998) [13],[30]. According to (G. M. Winch, 2003) [31] today's engineering and construction industry model was in many methods following World War II. Its construction is "industrial" in nature and established on the "serial specialization" that existed in producing at that time. But the 21st century is not like the late 20th century and experience in supplementary industry sectors has innovation. Construction is usually described as a less innovated industry, one that fails to revolutionize in comparison to supplementary sectors (G. M. Winch, 2003) [31]. Innovation, that according to (Firth \& Mellor, 1999) [11] way the request of new knowledge to industry including new produce, new procedure, social and organizational innovation, is consequently desirable.

The Movement for Innovation seizes the lead in advancing Rethinking Construction amongst the nonhousing sectors of the UK Construction Industry and connected transactions and expert organizations. The Board of Management is accountable for the presentation and discovering outputs from the Movement for innovation demonstration Projects, and has managed the innovative of the Key Presentation Indicators and the Environmental Presentation Indicators. Movement for innovation is growing the local web for Rethinking Construction, across its demonstration undertakings cluster programme (Thirwall et.al, 2002). These clusters are nowadays increasing to embrace the Housing Forum Demonstration Projects. Movement for innovation is advancing Rethinking Construction events, such as off-site fabrication, Knowledge Management and Lean Construction via seminar and conference.

\section{Innovation In Construction Industry}

The belief on 'innovation' is quite an expansive one. People, firms, countries seek to innovate as a way to maintain relevance. A functional meaning is given by (Slaughter, 1998) [23]: Innovation is clearly discriminated from invention. Creation is a methodical design or ideal of a procedure or product that can clearly be discriminated as novel contrasted to continuing arts. Innovation is the actual use of a nontrivial innovation and enhancement in a procedure, product, or arrangement that is novel to the association growing the innovation. Innovation from a general perspective defines the creation of better or more effective products, processes, services, technologies, or ideas that are readily available to markets, governments, and society (Wiki, 2012) [27]. However, there is not a single and complete definition of innovation (Beliz, Carl, Ghassan, \& James, 2010) [4].

From the construction industry angle, (DTI, 2007) [8] defined innovation as 'successful exploitation of idea" and that "it is the key business process to compete effectively in the increasingly competitive global environment", (Ebgu, 2001) [10] concludes this idea as being new to the unit of adoption'. This new idea is being implemented in a construction work or project with the aim of getting additional benefits even if there might have been related risks and reservations. The new idea may be a new design, technology, and material component or construction technique used in a project. Innovation in the construction industry can seize countless forms. (Slaughter, 1998)[23] Characterizes such innovation according to whether it is 'incremental' (small, and established on continuing experience and knowledge), 'radical' (a breakthrough in science or technology), 'modular' (a innovation in believed inside a constituent only), 'architectural' (a innovation in links to supplementary constituents or systems), or 'system' (multiple, consolidated innovations). Innovation in its many forms; for instance radical, may be in response to crisis or pressure from the external environment, or in its incremental form; where gradual changes are made commonly (Salman, Pau, Wei, \& Dainty, 2005) [20]. In construction industry being a project-based industry, it is not uncommon to experience two types of innovation; either an incremental one or a systemic one.

"Incremental innovations are those that underpin the accessible product or process and provide a quantifiable impact on productivity (e.g., transitioning from stick-built construction to the use of prefabricated wall trusses in homebuilding). In the case of incremental innovations, productivity for individual components can increase while overall productivity may increase, decline, or remain unchanged."

"Systemic innovations, on the other hand, refer to innovations that reinforce the existing product but necessitate a change in the process that requires multiple firms to change their practice. Systemic innovations typically enable significant increases in overall productivity over the long term. But these may create switching or start-up costs for some participants, and reduce or eliminate the role of others. Examples of systemic innovations include virtual design and construction, supply chain integration, and prefabricated subcomponent wall systems in homebuilding (Taylor \& Levitt, 2004) [25]."

Construction innovation is most functionally believed inside a colossal 'product-system' perspective. This outlook encompasses the construction industry as normally understood, including contractors and consultants, jointly with a scope of supplementary contestants that are believed vital to construction innovation, 
but do not form portion of standard research of the industry. These contestants contain clients, manufacturers, watchdogs and technical prop providers(Blayse \& Manley, 2004) [5]. Innovation in the industry can be functionally leveraged across the pursuing activities:

- Enhancing client association, across elevated levels of technical competence, elevated demand outlines, and prudent risk-taking;

- Building robust connections with manufacturers supplying the industry, in think of their involvement in R\&D programs;

- Mobilizing consolidated ways to construction undertakings, in reply to the fragmentation of the industry emerging from the 'one-off' nature of most undertakings and the proliferation of tiny players;

- Improving vision flows, by growing extra intensive industry connections to offset the disadvantages of creation established on provisional coalitions of firms;

- Integration of undertaking experiences into constant company procedures to check the defeat of unspoken vision amid projects;

- Active use of innovation brokers to enable effectual admission to technical prop providers, and supplementary external contestants with complementary vision bases; advancing innovative procurement system, including partnering or forming an alliance, to enhance cooperative problems resolving, the adoption of non-standard resolutions, and equitable allocation of risk;

According to (G. Winch, 1996) [29] the firms and the institutional context in which the contracting system is operated has been in a mutually constituted through time. Due to distinctive contracting system the projects are shown to be governed by risk shedding, cost control-controlling system whereas in the French projects the contracting system leads to cost reduction system and risk sharing. Thus this new innovation strategy has made the organization globally competitive.

It is increasingly consented that construction innovation encompasses an expansive scope of members inside a 'product system' (Marceau et al 1999). Clients and producing firms are key industry members in words of steering innovation. Clients are usually believed to have large capacity to exert impact on firms and people encompassed in construction in a manner that fosters innovation. Clients are able to enhance innovation in construction in a number of ways. They can recognize specific novel necessities to be supplied by developers, constructing product suppliers, contractors and operators(Seaden \& Manseau, 2001) [21]; exert pressure on undertaking members to enhance buildings' lifecycle presentation, finished characteristics and undertaking flexibility to cope with unforeseen adjustments (D. M. Gann \& Salter, 2000) [14]; and usually demand higher standards of work (Barlow, 2000).

The adoption and integration of innovative products can need substantial innovation on the construction or building locale as these innovative products have to be consolidated into pre-existing subsystems or complex product system. Methods and procedures of connection could have to be innovative and the skills set of the workers could not be adequate to deal with the new innovative products.

The construction sector whether or not they industrialized new or considerably improved products, that are the method the innovation question is most frequently phrased in innovation surveys, was arbitrated to be an improper one for construction industries because the intention of the construction creation arrangement is not to produce innovative produce but rather to assemble complex product systems. The extra critical question is, if one wants to learn innovation in construction industries is that of the obstacles to and encounter of the flow of innovative products into construction industries, as well of the extent of the diffusion of precise key innovative products. Thus it is very important to analyze on the difference between the differences in mechanisms of the sector and the role of innovation that emerge between traditional, hierarchical and project based organizations.

\section{Examples of Innovations In Construction Industry}

Since 1957 Malaysia has gone through rapid innovation in the field of engineering practices, and construction has also piled its growth. The experience gained in some major civil projects in Malaysia like Penang Bridge, North-South Expressway, and PETRONAS Twin Towers innovation led have been possible with the help of high capacity RC (Reinforcement concrete) spun piles, understanding of arching mechanisms, and to predicting the capacity of the piles and diagnosing the piles conditions.

Even though the engineering and construction industry is the largest industry in the world, yet the productivity of the traditional sectors used has been laggard as compared to other industrial sector. But in the $21^{\text {st }}$ century other industrial sector has experienced a significant growth in productivity due to use of systematic innovation. Malaysia saw a high increase in the construction sector during $8^{\text {th }}$ and 9 th plan. It was found that the growth of construction sector in $8^{\text {th }}$ plan was only $1 \%$, whereas in the $9^{\text {th }}$ plan it increased to $4 \%$. But in $10^{\text {th }}$ plan (2011 - 2015) the spirit of Malaysia to create a fair and socially with national unity as a ultimate objective. Thus the scope of investment will be broadened from oil and gas sector and plantations to the construction and service sectors. And it is more likely to increase the growth of construction sector in the $10^{\text {th }}$ plan as compared to the $8^{\text {th }}$ 
and $9^{\text {th }}$ Malaysia plan. Systemic approaches are giving new insight into innovative and economic performance, but the interaction between technology innovative and innovation system (OECD, 1997). Another example of systematic innovation can be experienced with a joint venture project of smart tunnel of 9.7 kilometer long water diversion tunnel to alleviate monsoon floods showing a talent for novel engineering (enr.com, 2005). Thus through this approach it is viable to investigate on the role of systematic innovation that can increase productivity of engineering \& construction industries of the world.

With the significant example of innovation in Malaysia construction industry; "Stormwater Management And Road Tunnel" (SMART) which has a reputation of being the longest storm water tunnel in south-East Asia, the second longest in Asia and also got a UN Habitat Scroll of Honour Award for its innovativeness (Wiki, 2012) [28], other innovations observed in the construction industries are; khalifa tower in Dubai (the tallest man-made structure in the world).

\section{Systemic Innovation In Construction Industry}

Innovation is critical to renewal of industries and systemic innovations produce the largest productivity gains. Studies have shown that extra industries are traveling from useful hierarchies to undertaking forms of management whereas innovation is not as well understood and whereas systemic innovations diffuse extra slowly. Taylor \& Levitt, (2004) [25] opined that as such the understanding of barriers to systemic innovation is of producing significance not merely to our industry but additionally to many of our client's industries. Though, the engineering and construction industry as on par with producing after incremental innovation is believed (minor adjustments in product) is a laggard in systemic innovation here several firms have to innovation their processes. Plainly locale, we have an innovation deficit, one whereas we tolerate to mainly produce from past innovation efforts but additionally one whereas we are spreading extremely insufficient new seeds. Industry expansive systemic innovations promoted by consistent kinds of adjustments across the engineering and construction industry's self coordinating networks. These modified could flow from a little of the systemic subjects the industry is nowadays confronting or could flow from nationwide imperatives. They will be more promoted by a clear understanding of the procedure by that network adopt new innovations.

The idea of systemic innovation is not considered as a new innovation for the world market. R. Buckminster Fuller from U.S. who built Dymaxion house that would solve the need for a mass produced, affordable and environment efficient houses first invented it in 1927. (Taylor \& Levitt, 2004) [25] stated in their study that systemic innovation requires many organizations to innovate in the form of advances in supply chain management, increasing use of enterprise resource planning (ERP), and the prefabrication component systems. (Ortiz, Pasqualino, \& Castells, 2010) [17] Conferred that in the domain of supply chain management there is an important role of lean production techniques that is used widely in the construction and engineering sector.

Systemic innovation, as discussed earlier differs from an incremental innovation basically because "it requires multiple specialist firms to change their process in a coordinated fashion" (Prieto, 2009) [19]. Systemic innovations give some of the biggest productive gains in the industry.

Examples of systemic innovations in the construction industry include;

- 3D CAD virtual design and construction tools

- Prefabrication of building or component systems

- Modularization

- Integrated supply chain management

- Building Information Modeling (BIM)

- Plumbing \& electrical components replacing conventional stick-built lumber wall frame

- $\quad$ Project Finance Initiatives (PFI) and Public Private Partnerships (PPP)

Some attributes are generally common to industries that have successful systemic innovation. They include; relational stability, combined corporate interest, boundary ability or strength, network level change agents (Taylor \& Levitt, 2005) (Prieto, 2009) [26][19]. Take for instance in 3D CAD implementation in construction works, (Taylor \& Levitt, 2005) [26] identified these attributes to be accounted for the successful implementation. Summary of these attributes are given below

Relational stability: this is the ability to maintain a stable relationship with the specialists that involve in the organizations in the industry. This boosts the chances of making a systemic innovation. (Taylor \& Levitt, 2005) [26] Therefore made a proposition that "the weaker the relational stability in an inter-organizational network, the greater the difficulty to achieve network-level learning. This contributes to slower systemic innovation diffusion rate. In the case of stronger relational stability, network-level learning is easy, which accounts for a fast diffusion of systemic innovation.

Interest: this is relates to the interest an inter-organizational network. Firms that consider their interest only may have it difficult to diffuse systemic innovations; otherwise, diffusion takes place easily. 
Boundary strength: boundary strength between firms in a network needs to be flexible to adapt to systemic innovations. This contributes to faster systemic innovation diffusion rates. In the case of rigid boundary strength, systemic innovation diffuses slowly.

Network level change agents: change agents are needed at the network level to propagate the flow of system innovation. Where they are absent, diffusion slows down.

Comparison was made by (Taylor \& Levitt, 2005) [26] between U.S and Finland construction industries in terms of the attributes that aid systemic innovations as earlier discussed. This was represented in a table as shown below;

Table 3.1 - comparing construction networks in United States and Finland.

\begin{tabular}{|c|c|c|}
\cline { 2 - 3 } \multicolumn{1}{c|}{} & \multicolumn{2}{c|}{ Country in which Construction Network Exists } \\
\hline Construct & United States & Finland \\
\hline Relational Stability & $\begin{array}{c}\text { Weak } \\
\text { (Tendency to contract from 5-6 } \\
\text { firms per specialist type) }\end{array}$ & $\begin{array}{c}\text { Strong } \\
\text { (Tendency to contract from 1-3 } \\
\text { firms per specialist type) }\end{array}$ \\
\hline Interests & Firm & Network \\
\hline Boundary Strength & Rigid & Fluid \\
\hline $\begin{array}{c}\text { Agent for network-level } \\
\text { change }\end{array}$ & None & National Technology Funding \\
Agencies
\end{tabular}

Source: Modeling Systemic Innovation in Design and Construction Networks (Taylor \& Levitt, 2005) [26]

\section{The Barriers To Systemic Innovations Are Therefore Discussed Below}

The key problem with innovation in the construction industry is the organization of the construction process. (Atkin, et al., 1996) [2] Argues that the traditional mode of organization of construction makes the supplier insufficient on expertise, decrease innovation related to design and perpetuates innovation traditional practices that also inhibit investment in the innovation process of construction sector. For such a reason, (Lu \& Sexton, 2006) [16]conferred that the weak capacity of this organizational innovation in the construction industry decreases the competitiveness, economic growth and living standards of people. They draw the key features of innovation in construction and analyze the impact of the structure and organization of construction towards success and failure of new technologies

Malaysian construction industry is below a steady pressure to update and to reform. Lack of knowledge on building systems and green construction, low quality finishes on constructions and infrastructures, poor presentation by contractors, the demand to enhance on procurement strategy, and lack of partnering initiatives are a little of the oftentimes subjects increased in meetings, sessions, workshops and seminars by clients and stakeholders in Malaysia (Hamid \& Kamar, 2010) [15].

The act of knowledge transfer in the innovation of construction firms in is poorly understood, and there is a clear demand to rectify this (Atkin, Winch, \& Slaughter, 1996) [2]. Presentation enhancement established on knowledge absorbed into construction firms across knowledge transfer does transpire successfully. Though, firms demand to comprehend and grasp knowledge transfer attention to safeguard consistent success. Chanted and Gibson (2000) recognized the pursuing variables as altering the degree of accomplishment in the procedure and aftermath of knowledge transfer: person-to-person contacts; knowing whom to contact; collection of contact channels; set up transfer workplace or committee; a sense of public purpose; understanding of the nature of the business; attitude and values; rise in awareness of transfer; concreteness of knowledge/technology; formation of a cooperative research program; clear meaning of transfer; ability of incentives for transfer and product champions.

However, present construction industry knowledge transfer endeavors are being harshly hindered by a lack of proper understanding of such knowledge transfer subjects and their interrelationships to both firm skills and procedures, and the vision characteristics of the technologies being transferred; in particular (Sexton \& Barrett, 2003) [22]. First, present ways incline to think knowledge transfer as a mechanistic "pick and- mix" exercise - recognizing new technologies, and trying to insert them in their continuing form into (unsurprisingly) unreceptive construction firms. . Second, present knowledge transfer mechanisms are not sufficiently notified by, or involve with, firm crucial association and organizational skills and procedures vital to enable them to absorb technologies and to coil them into appropriate innovations. Experience from the producing sector, for example, has stressed that the capacity of firms to comprehend and efficiently use new technologies from 
external origins is deeply affected by the level of prior-related vision and expertise (Alder and Shenhar, 1993). Finally, present knowledge transfer mechanisms do not fully worth both the skill and motivation for construction firms to absorb and use new technologies are considerably affected by the vision characteristics of the technologies. "Hard" technologies that are described by explicit vision need extremely disparate diffusion mechanisms and organizational skills and procedures than those needed for "soft" technologies that are unspoken in nature.

The implications of these barriers for knowledge transfer in tiny construction firms crystallizes the systemic nature of knowledge transfer, and can be fruitfully believed, as a "technology transfer system". Procedure innovation in construction is of three types: logistical technologies (bringing produce to the site), locale arranging (preparing the land) and amassing technologies (putting the constituents jointly to craft the final structure). Innovation in heavy supplies and construction instruments are key drivers of innovation on the construction or building locale, with the innovative new connection practices. As in the case of produce, machinery and supplies are produced in the producing sector, not in the construction industries and new supplies and machinery can additionally need momentous adjustments on the work locale in words of connection habits and the skill sets of the operatives (Anderson \& Schaan, 2001) [1].

According to Knight (1996), taxation of new products, procedures and services that is experiencing the transition to maximum commercialization, deeds as a barrier. Improper power tax is perceived as a barrier as it restrains innovation(Pihkala, Ylinenpaa, \& Vesalainen, 2002) [18]. Power interference and mismanagement scares away financiers in the state, nurtures insecurity and increases risk. Adjustments in the construction of globe economies increase speculation in companies and stifle investment in R\&D vital for innovation. Hostility towards company from the area of judiciary and power that could stem from a lack of public belief and contact (Knight,1996). Fragmentation and low level of investment in R\&D are a little of the key barriers to innovation but there are supplementary vital factors. Though, the barriers and enablers of hobbies that prop innovation in the construction industry have not been sufficiently learned and quantified. So distant, there has been extremely slight in-depth research study of various innovation framework factors connected to the construction industry (Seaden \& Manseau, 2001). [21] The level of training in science, engineering and technical education and level of research study and innovative at the nationwide level are looked at as the biggest enablers to innovation in building that will drive onward productivity. Other barriers found by (Anderson \& Schaan, 2001) [1] are stated as; lack of expertise, inability to train workers within the time frame, lack of technical support, and inability to support new products and equipments. The equipment installation that is considered as a systemic innovation tool was found to have highest inability legally, with restrictive codes and standards.

Summarily, we can see these barriers as; traditional organization processes, taxation on innovative products going to be commercialized, lack of expertise and technical support, knowledge transfer, investing in $\mathrm{R}$ $\& \mathrm{D}$ among others.

\section{Solutions}

Having shown the barriers that make systemic innovations occur in construction industry, with the impact they keep having on the industry, a way out is desirable so as to reposition the industry to be productive. Therefore, some solutions are written out below. R\&D at the nationwide level increases the knowledge intensity of the procedures of generating, producing and commercializing new goods and services and fosters innovation in disparate fields (Freeman \& Soete, 2009) [12]. Training in science and engineering education and an exceedingly trained workforce in the relevant fields of science, engineering and management is associated with innovation at the nationwide level.

Importing knowledge and science can ease pressure on the labor market. Roads and supplementary transport groundwork furnish the way, by that new products and services can be delivered. Native demand and export possibly impact the degree of innovation in the industry. Works indicates that innovation has been attained in a little case due to marketplace demand-pull. Globalization inspires larger participation and integration of globe transactions, open-minded power strategies, changing company strategies and conception of globe capital markets. Multinationals frolic a key act in disseminating knowledge concerning the globe (Freeman \& Soete, 2009) [12]. (Slaughter, 2000) [24] Quoted that " research on construction innovation provides the basis to expand the current understanding on innovation implementation process in order to improve company's long term competitive strategy. (Slaughter, 2000) [24] Provided six stages of innovation activity i.e. identification, evaluation, commitment, preparation, commitment and post use evaluation and argues that the framework increases the capacity of the construction related organizations in order to implement and develop innovation in the built environments. 


\section{Conclusion And Recommendation}

The type of innovation need to be adopted may depend on the industry and the project being engaged in. Information is also vital, especially when it comes to business information in the construction industry. Apart from increasing performance, it helps determine the type of innovation to adopt. Therefore, recommendations are given below, leading to a conclusion.

The strategy of hiring graduates would develop employee skills and knowledge and also would improve technological capabilities. There is a need of technological innovation for increase in the quality and success of the industrial sector. Thus the rise of professionalized industrial R\&D system would transfer the technology and would solve issues for the industry. The practice of engineering and construction encourages innovation in order to value add and be competitive.

The discussion of construction systemic innovation strategy implementation provided detailed insights from the literature to help us understand what these implementation drivers and barriers might be; however, most studies in the literature were shown to lack focus on the actual implementation phase. This suggested a need for research into both innovation diffusion factors and an implementation processes approach. The paper thus helps us to understand how to encourage and manage the process of actual implementation of technology within construction and engineering organizations through systemic innovation.

Innovations demand champions. People grasp thoughts, and thoughts are the rallying point concerning that collective deed mobilizes. Unless the 'systems integrator' is convinced of the merits of the new believed, and has the skills to incorporate it into the arrangement as a finish, innovation is probable to be slow. The qualities of champions demand to contain ownership, at the extremely least, of manipulation and technical competence. This is because elevated levels of technical competence enable champions to vanquish the uncertainty of Construction innovation, and their power enables them to trial confrontation to innovation (Nam and Tatum 1997). Insufficient firms in the Construction industry have the resources or incentives to uphold a proper research and innovative program. This indicates the significance of competent implementation procedures to enable firms to prosperously accept innovation industrialized elsewhere. It has been shown that this involves, in portion, absorptive capacity, champions, sophistication, vision codification, innovation brokers and connections alongside manufacturers. Competent innovation presentation at stable level needs joining agents such as these into a proper innovation strategy. The final form of the strategy will be a purpose of the number and quality of organizational skills (Walker et al 2003).

The bottom line is that; engineering and construction firms need to innovate to win projects and to improve the financial results of these projects. They must innovate to compete. Innovative and effective use of new technology can provide important competitive advantages for engineering and construction firms. These advantages stem from distinctive technical capability, improvements in operations, and image as a technically innovative company.

\section{References}

[1] Anderson, F., \& Schaan, S. (2001). Innovation, advanced technologies and practices in the construction and related industries: National estimates. Statistics Canada/National Research Council of Canada, Canada.

[2] Atkin, B., Winch, G., \& Slaughter, ES. (1996). Innovation in the construction sector. Whitley, R, and Kristensen, P.(1996) The Changing European Firm: The Limits of Convergence. London: Routledge.

[3] Barlow, J. (2000). Innovation and learning in complex offshore construction projects. Research Policy, 29(7-8), 973-989.

[4] Beliz, O., Carl, A., Ghassan, A., \& James, P. (2010). Innovation in Construction: a Project Life Cycle Approach. Salford: University of Salford.

[5] Blayse, A.M., \& Manley, K. (2004). Key influences on construction innovation. Construction Innovation: Information, Process, Management, 4(3), 143-154.

[6] BusinessDictionary. (2012). Construction industry. Retrieved August 26, 2012, from Business Dictionary: http://www.businessdictionary.com/definition/construction-industry.html

[7] DOL. (2012). Construction Industry. Retrieved August 26, 2012, from Occupation safety \& Health Administration, United states Department of Labor: http://www.osha.gov/doc/index.html

[8] DTI. (2007). Innovation in Services. London: Department of Trade and Industry.

[9] Dulaimi, M.F., Ling, F.Y.Y., Ofori, G., \& De Silva, N. (2002). Enhancing integration and innovation in construction. Building Research \& Information, 30(4), 237-247.

[10] Ebgu, C. O. (2001). Knowledge management and human resource management (HRM); the role of the project manager. Proceedings of Fourth European Project Management. London.

[11] Firth, L., \& Mellor, D. (1999). The impact of regulation on innovation. European Journal of Law and economics, 8(3), 199-205.

[12] Freeman, C., \& Soete, L. (2009). Developing science, technology and innovation indicators: What we can learn from the past. Research Policy, 38(4), 583-589.

[13] Gann, D. (2000). Building innovation: complex constructs in a changing world: Thomas Telford Services Ltd.

[14] Gann, D.M., \& Salter, A.J. (2000). Innovation in project-based, service-enhanced firms: the construction of complex products and systems. Research Policy, 29(7-8), 955-972.

[15] Hamid, Z. A., \& Kamar, K. A. (2010). Modernising the Malaysian Construction Industry through Innovation. CIB World Congress 2010. Salford.

[16] Lu, S.L., \& Sexton, M. (2006). Innovation in small construction knowledge-intensive professional service firms: a case study of an architectural practice. Construction Management and Economics, 24(12), 1269-1282. 
[17] Ortiz, O., Pasqualino, JC, \& Castells, F. (2010). Environmental performance of construction waste: Comparing three scenarios from a case study in Catalonia, Spain. Waste Management, 30(4), 646-654.

[18] Pihkala, T., Ylinenpaa, H., \& Vesalainen, J. (2002). Innovation barriers amongst clusters of European SMEs. International Journal of Entrepreneurship and Innovation Management, 2(6), 520-536.

[19] Prieto, B. (2009, May). The Engineering \& Construction Industry Innovation Deficit: Is the E\&C Industry Model Broken? Collaboratory for Research on Global Projects . Stanford, california, US: Stanford University.

[20] Salman, A., Pau, 1. F., Wei, P., \& Dainty, A. R. (2005). Learning to innovate in construction: a case study. Proceedings of the 21st Annual ARCOM Conference, (pp. 1215-1224). London.

[21] Seaden, G., \& Manseau, A. (2001). Public policy and construction innovation. Building Research \& Information, 29(3), $182-196$.

[22] Sexton, M., \& Barrett, P. (2003). A literature synthesis of innovation in small construction firms: insights, ambiguities and questions. Construction Management and Economics, 21(6), 613-622.

[23] Slaughter, E.S. (1998). Models of construction innovation. Journal of Construction Engineering and management, 124(3), 226-231.

[24] Slaughter, E.S. (2000). Implementation of construction innovations. Building Research \& Information, 28(1), 2-17.

[25] Taylor, J., \& Levitt, R. (2004). Understanding and managing systemic innovation in project-based industries. Innovations: Project management research, 83-99.

[26] Taylor, J. E., \& Levitt, R. (2005). Modeling Systemic Innovation in Design and Construction Networks. Stanford: Stanford University.

[27] Wiki. (2012, August 22). Innovation. Retrieved August 26, 2012, from Wikipedia: the free encyclopedia: http://en.wikipedia.org/wiki/Innovation

[28] Wiki. (2012, August 17). SMART Tunnel. Retrieved August 26, 2012, from Wikipedia: http://en.wikipedia.org/wiki/SMART_Tunnel

[29] Winch, G. (1996). 10 Contracting systems in the European construction industry. The changing European firm: limits to convergence, 241.

[30] Winch, G. (1998). Zephyrs of creative destruction: understanding the management of innovation in construction. Building Research \& Information, 26(5), 268-279.

[31] Winch, G.M. (2003). How innovative is construction? Comparing aggregated data on construction innovation and other sectors-a case of apples and pears. Construction Management and Economics, 21(6), 651-654. 